\title{
A ERA DAS IMAGENS E AS TRANSFORMAÇÕES DO SER CONTEMPORÂNEO NA PERSPECTIVA DE WALTER BENJAMIN E VILÉM FLUSSER
}

Lia Freitas Oliveira

\begin{abstract}
RESUMO
A fotografia inaugurou uma nova etapa para a civilização humana: a era das imagens técnicas. A maneira como o homem contemporâneo compreende o mundo e a si mesmo mudou substancialmente graças a esse avanço técnico. Assim, Walter Benjamin e Vilém Flusser compreendem o complexo alcance dessa transformação, captando o cerne ontológico da virada de paradigma iniciada desde meados do século XIX. Desde então, o homem guia-se no mundo e se expressa através de imagens, criando uma individualidade fragmentada e dispersa. Hoje, entender as imagens significa entendermos nós mesmos e toda a teia cultural que integramos.
\end{abstract}

Palavras-chave: Imagem. Walter Benjamin. Vilém Flusser

\section{THE ERA OF IMAGES AND THE TRANSFORMATIONS OF CONTEMPORARY BEING IN THE PERSPECTIVE OF WALTER BENJAMIN AND VILÉM FLUSSER}

\begin{abstract}
Photography has inaugurated a new stage for human civilization: the era of technical images. The way in which contemporary man understands the world and himself has changed substantially thanks to this technical advance. Thus, Walter Benjamin and Vilem Flusser understand the complex scope of this transformation, capturing the ontological core of the paradigm shift initiated since the mid-nineteenth century. Since then, man has been guided in the world and expressed through images, creating a fragmented and dispersed individuality. Today, understanding the images means understanding ourselves and the whole cultural web that we integrate.
\end{abstract}

Keywords: Image. Walter Benjamin. Vilém Flusser 


\section{Introdução}

Estamos vivendo, inegavelmente, a era das imagens. Estas fazem parte do cotidiano não só porque nos rodeiam em todos os lugares e momentos, mas principalmente porque passamos a entender o nosso próprio cotidiano a partir das imagens. Elas são as lentes com as quais deciframos e experimentamos o mundo. As imagens impelem não só a visão, mas o corpo todo do ser contemporâneo a se comportar de uma maneira muito única, ainda não vivenciada na história da humanidade. Apesar da imagem ser um fenômeno cultural que nos acompanha desde a pré-história, vivemos um momento no tempo em que as imagens passam a existir dentro de um novo referencial ontológico. Tal referencial nasce junto com a criação da técnica fotográfica no século XIX.

Quando se fala sobre o surgimento da fotografia e as transformações estruturais que essa revolução causou à cultura, é impossível não lembrarmos o nome de Walter Benjamin e sua preocupação em compreender como tal desenvolvimento técnico interferiu no ser da modernidade. Para Benjamin o surgimento da fotografia significa um rompimento cultural profundo, que abalou as estruturas não só da arte, mas da política e da moral. Benjamin viu a ponta do fenômeno e conseguiu rastrear e compreender a estrutura profunda que lhe servia de base, o que proporcionou uma incrível compreensão sobre o que estava por vir, o qual o filósofo, infelizmente, devido sua morte precoce, não pôde vivenciar.

As previsões benjaminianas sobre as intensas e complexas transformações que a fotografia traria, não vieram em sua filosofia através de uma análise lógica objetiva. Benjamin trouxe ao seu texto a característica fragmentária das próprias imagens que analisava. O que, em absoluto, fez sua escrita menos rigorosa. É por entender tão lucidamente a estrutura imagética dessa nova sociedade que nascia, que o autor preservou tal estrutura também em sua teoria. Assim, a filosofia de Walter Benjamin tem uma importância fundamental no que diz respeito aos estudos sobre cultura moderna e à compreensão dos primeiros indícios definidores da cultura contemporânea. Por isso, é necessário a continuação de uma filosofia que pense sobre a imagem 
fotográfica e compreenda o fundamento ontológico das transformações provocadas pelo avanço técnico da fotografia.

Por conseguinte, quando pensamos em uma "Filosofia do futuro" que leve em consideração o tema da fotografia, nos deparamos imprescindivelmente com a perspectiva de Vilém Flusser, filósofo contemporâneo que dedicou boa parte de sua teoria ao estudo da imagem e todas as suas reverberações na contemporaneidade. A fotografia, a comunicação e o design foram a tônica de seus estudos e, por isso, sua ligação com Walter Benjamin é inevitável. Flusser retomou inúmeras temáticas trabalhadas por Benjamin no que concerne ao estudo das imagens produzidas pelos aparelhos fotográficos. Uma delas é sobre o conceito de imagem técnica como dimensão do eterno retorno. Ou seja, as imagens técnicas são produções programadas para serem superfícies de sonhos. O conceito benjaminiano de inconsciente ótico coaduna com a perspectiva de Flusser, pois para ambos as imagens possuem um valor mágico dentro da cultura. Essa magia é conferida - por mais contraditório que possa aparentar - pela potencialidade técnica do aparelho fotográfico.

Partindo de tais pressupostos, ambos notaram a possibilidade revolucionária e a virada copernicana que a imagem fotográfica conferiu à cultura. Revolucionou muito mais do que somente a arte, ou a política, mas criou um novo modo de ser no mundo, que não está mais amparado em antigos paradigmas fundadores da civilização. A perspectiva fragmentária inaugurada por essa mudança esfacelou o mundo e criou incontáveis outros, estabelecendo uma nova concepção sobre realidade, natureza e humanidade.

Benjamin não vivenciou a era digital, mas a anunciou. Flusser não só viveu, como a compreendeu de maneira tão clara, que percebeu a urgência de começar a desenvolver uma filosofia que trate fundamentalmente dessas questões, deixando para trás a antiga concepção de que são temas a serem pensados somente no âmbito estética filosófica. Vivemos um mundo conectado por redes de informação e não é mais possível pensarmos de maneira categorial como a modernidade. Assim, refletir sobre as imagens é refletir sobre quem somos e mais ainda, refletir sobre o que sempre sonhamos ser. 


\section{As imagens técnicas}

Imagem não é uma novidade moderna. Desde a pré-história os homens produzem imagens para expressar e decodificar o mundo. A pintura rupestre, as imagens divinas, todas estas tinham um valor central na cultura dos primeiros homens. Para compreender como chegamos a produzir as imagens técnicas a fotografia, o cinema, as imagens digitais, etc. - é preciso conhecer a caminhada milenar da expressão simbólica da consciência humana. Flusser entende que o tempo da humanidade está dividido em três etapas: a pré-história, a história e a pós-história. Todas estas são definidas pelos símbolos decodificadores do real criados em cada uma. Na pré-história os homens decodificavam o mundo através das imagens tradicionais. A história surge quando os homens criam a escrita e passam a entender o mundo de uma forma bem distinta da anterior. A terceira, a pós-história, é inaugurada com a criação da técnica fotográfica. As imagens pré-históricas demonstraram-se bem diferente das imagens atuais, embora tenham em comum o fato de que ambas são redutos de magia. Por que, então, imagens sempre são mágicas?

As imagens são superfícies inseridas no tempo e no espaço e sempre representam algo. Por ter um caráter plano, só possuem duas dimensões, o que não as impede de simular as quatro dimensões da realidade. No entanto, por serem superfícies planas, as imagens têm um território fixo. Por mais que possamos pensar no cinema, ou na televisão, como espaços onde essas imagens estão em movimento, elas são fixas porque são sempre um recorte, um momento que não é contínuo. Dessa maneira, o olho as vê por um escaneamento cíclico. Olhar imagens é sempre retornar para pontos já percebidos antes. Flusser diz: "O tempo projetado pelo olhar sobre a imagem é o do eterno retorno. O olhar diacroniza a sincronicidade imaginística por ciclos". (FLUSSER, 2011, 16). Significa que quem cria as relações lógicas ou causais não é em primeiro lugar a imagem, mas o olho, pois o tempo da imagem é o tempo da magia: um tempo cíclico que à medida que gira, vai estabelecendo relações significativas. 
As imagens não eternizam eventos, ela os transforma em cenas. Mesmo que a cena fixe algo que antes não era fixo, pela propriedade plana da imagem, ela favorece que os elementos da cena, através do escaneamento do olho, estabeleçam relações significativas sempre novas, criando o movimento dialético interno da imagem. O olho que inspeciona a superfície da imagem está eternamente retornando ao sempre mesmo e o dotando de muitos significados, ou seja, produzindo magia.

Através da dialética do olhar, as imagens vão interpretando o real segundo sua magia inerente desde a pré-história. Colocaram-se como mediações entre homem e mundo e por isso o mundo do homem pré-histórico era um mundo mágico. No entanto, essas imagens que serviriam aos humanos como uma espécie de direcionamento, acabaram por virar biombos (FLUSSER, 2011, 17). Isto é, o homem ao invés de decifrar a realidade por elas, passou a ver o mundo como imagem. Os olhos foram completamente encobertos por sua superfície turva. Segundo Flusser, nasce aí a idolatria (FLUSSER, 2011, 17), pois a humanidade deixou de se servir das imagens para viver em função delas. Afim de escapar dessa função alucinatória, surge no segundo milênio a.C. a escrita. Flusser compreendeu que a escrita é mais uma mediação entre homem e mundo. Os símbolos que antes eram imagéticos, passaram a sair do plano e a tornarem-se lineares. Perderam o caráter de eterno retorno e logo criaram uma nova relação significativa: cronológica e causal. Assim, os homens passaram a "rasgar"1 as imagens:

O método do rasgamento consistia em desfiar a superfície das imagens em linhas e alinhar os elementos imaginísticos. Eis como foi inventada a escrita linear. Tratava-se de transcodificar o tempo circular em linear, traduzir cenas em processos. Surgia assim a consciência histórica. (FLUSSER, 2011, 18)

A história nasce graças à sucessão de símbolos², fazendo o homem compreender o mundo também como uma sucessão de fatos. A consciência

\footnotetext{
1 Interessante o uso de Flusser do termo "rasgar", pois remete não só ao sentido literal que o autor usou, mas a outros referenciais como 0 ato iconoclasta de rasgar imagens afim de romper com ilusão idólatra.

2 Percebemos a saída gradativa da realidade imaginística para a mediada pela escrita, pois as primeiras escritas (a cuneiforme do povo mesopotâmico, por exemplo) tinham a peculiaridade de parecerem com desenhos, os signos linguísticos ainda estavam ligados as imagens do mundo. Mestre em Filosofia pela Universidade Estadual do Ceará. Pesquisadora do Grupo "Walter Benjamin e a Filosofia Contemporânea" (Cnpq). Brasileira, residente em Fortaleza-CE. Email: 
mágica foi deixada de lado e a escrita transformou os planos em retas, abstraindo todas as dimensões. A única dimensão da escrita é a conceituação. Consequentemente, a interpretação do mundo contou com mais uma camada. A escrita não substituiu as imagens mediadoras. Ela passou a se interpor entre homem e imagem, por isso a escrita é tão abstrata e afastou mais ainda o homem do mundo concreto.

O processo de rasgamento das imagens se fez na tentativa de explicá-las dentro de parâmetros lógicos, lineares e progressivos. Destituir de qualquer falseamento os significados contidos na imagem, para esmiuçá-los no texto. Por isso textos não substituem imagens, textos sempre elucidam imagens. Porém, imagens também podem ilustrar textos. Essa dialética é fundamental para que a produção de significado humana nunca estagne. Contudo, Flusser diz que esse movimento em um dado momento deixou de acontecer e houve um processo parecido com a pré-história e as imagens: os textos se enrijeceram a tal ponto, que não era mais possível reconstituir imagens a partir deles. Tornaram-se extremamente abstratos, vazios e absolutos, não restando mais nada para explicar. Tal crise é resultado de uma textolatria: "(...) tão alucinatória como a idolatria. Exemplo de textolatria é 'fidelidade ao texto', tanto nas ideologias (cristã, marxistas, etc.), quanto nas ciências exatas". (FLUSSER, 2011, 20)

O conteúdo imaginístico se desligou por completo dos textos, pois a imaginação - própria do universo das imagens que se transferia aos textos pela dialética das duas linguagens - passou a não ter mais espaço nenhum nos textos. A História se tornou um processo contínuo e progressivo de desmagicização do mundo, atingindo um nível de um desencanto quase completo. O mundo se tornou um lugar não mais de possibilidades, mas um universo de probabilidades e não sobrou quase nada ao homem a não ser o absurdo do cotidiano. Esse processo traz uma nova crise, a crise dos textos, e essa significa a derrocada da História e o início de uma nova fase: a pós-história.

Surgem as imagens técnicas na intenção de devolver imaginação ao mundo árido pela técnica, pelo texto científico. O mais interessante é que as

Só com o surgimento do alfabeto que a imagem se desligou e o processo da escrita se tornou mais abstrato. 
imagens técnicas, como o conceito já diz, são produtos da tecnologia, ou seja, produto de aparelho. Aparelhos são textos científicos transformados em objetos concretos. Significa que esse novo tipo de imagem são produtos indiretos de textos, o que retoma a dialética perdida no processo histórico de desencantamento. Há uma diferença não só de nível temporal, mas ontológico entre as imagens técnicas e as imagens tradicionais. Flusser comenta:

\begin{abstract}
Ontologicamente, a imagem tradicional é abstração de primeiro grau: abstrai duas dimensões do fenômeno concreto; a imagem técnica é abstração de terceiro grau: abstrai uma das dimensões da imagem tradicional para resultar em textos (abstração de segundo grau); depois, reconstituem a dimensão abstraída, afim de resultar novamente em imagem. Historicamente, as imagens tradicionais são pré-históricas; as imagens técnicas são pós-históricas. Ontologicamente, as imagens tradicionais imaginam o mundo; as imagens técnicas imaginam textos que concebem imagens que imaginam o mundo. Essa posição das imagens técnicas é decisiva para o seu deciframento. (FLUSSER, 2011, 24)
\end{abstract}

Isso significa que o nível da abstração das imagens técnicas é bem maior, pois elas são o resultado de muitas transcodificações. Entretanto, essas não aparentam necessitar de algum deciframento. As imagens técnicas, em sua grande maioria, se apresentam ao mundo não como cenas, mas como janelas para o real. São tão fidedignas ao que representam, que o olho não sente a necessidade de decodifica-la. Isso ocorre porque as novas imagens são produtos da técnica e carregam consigo a clareza e objetividade do texto científico em sua constituição. Assim, não deixa claro seu pressuposto ainda simbólico. Sua clareza é uma ilusão, pois as imagens continuam sendo superfícies mágicas e, cada vez mais abstratas e sofisticadas, enganam os olhos. Prometem uma maior proximidade entre homem e realidade, no entanto, fabricam um mundo cada vez mais virtual.

Por isso Flusser explica que entender em que grau de abstração as imagens técnicas estão é necessário para seu deciframento. ${ }^{3}$ Boa parte das

\footnotetext{
${ }^{3}$ A compreensão do grau de abstração das imagens é o que difere as imagens técnicas das imagens tradicionais. Mesmo que ambas possuam o caráter mágico, a diferença entre elas está no grau de abstração que cada uma, como representação, possui. A mediação das imagens tradicionais é quase "pura", ou seja, a representatividade de mundo ainda se dá de uma maneira mais concreta, pois existe apenas uma camada mediadora entre homem e mundo. As imagens técnicas, como produtos de textos, já se afastam bastante. Por isso sua capacidade de virtualizar o mundo é muito maior. Por essa razão a fotografia foi o primeiro passo para a era digital: o cinema, a televisão, a internet, são derivados deste princípio virtual das imagens.

Mestre em Filosofia pela Universidade Estadual do Ceará. Pesquisadora do Grupo "Walter Benjamin e a Filosofia Contemporânea" (Cnpq). Brasileira, residente em Fortaleza-CE. Email: 
pessoas não entendem essas etapas e o processo de transcodificação de que é resultado, criando certo alheamento e apatia na sociedade. Porém, quando entendemos tal processo, nos deparamos com o mundo conceitual e seu universo de significados. O risco de nos deixarmos enveredar por essas "janelas" e cairmos no abismo, pode nos fazer incorrer na mesma alucinação vivida pelos homens pré-históricos. Por isso Flusser diz que é preciso nos atermos às possibilidades de significados, compreendermos sua mágica.

A magia das imagens técnicas não quer modificar o mundo concreto, mas os conceitos que temos sobre o mundo. Toda imagem, tradicional ou técnica, é a ritualização de modelos. O modelo usado pelas imagens pré-históricas, por exemplo, é o mito. Os deuses criavam os modelos e os homens fixavam esses modelos em cenas, criando o ritual, a magia. Nas imagens técnicas o modelo é o texto científico da linguagem de programação. Flusser diz que entender o procedimento de transcodificação das imagens é vasculhar e captar o que se passa na câmara obscura do aparelho fotográfico.

A linguagem científica que cria as câmeras que usamos é a linguagem da programação, ou seja, da computação. Flusser define programa como um jogo de combinação entre elementos claros e distintos, ou seja, símbolos semânticos ou matemáticos. A permutação desses símbolos é feita com uma finalidade sempre funcional de resolver problemas e dar ao aparelho quase uma infinidade de saídas para qualquer adversidade que apareça. Então, no primeiro momento, o esforço maior está com o objeto, não com quem o manipula. O aparelho, portanto, é uma espécie de brinquedo que simula um tipo de pensamento - a permuta de códigos feita pelo programa. $\mathrm{O}$ homem que o manipula não o transforma em suas mãos, pois todas as resoluções de problemas estão préprogramadas, mas brinca, joga com o programa. No entanto, o autor ressalta: "Tal homem não brinca com seu brinquedo, mas contra ele". (FLUSSER, 2011, 37)

Flusser diz que o desenvolvimento técnico do capitalismo inaugurou uma nova fase no tipo de produção. A Revolução Industrial criou operários, homens que manipulavam máquinas. Maquinas são apêndices do corpo humano, no entanto, são completamente estúpidas. Por isso ainda precisam do homem para

\footnotetext{
Mestre em Filosofia pela Universidade Estadual do Ceará. Pesquisadora do Grupo "Walter Benjamin e a Filosofia Contemporânea" (Cnpq). Brasileira, residente em Fortaleza-CE. Email: 
manipulá-las. Aparelhos, por causa da linguagem programada, não são tão estúpidos. Eles aprendem conforme entram em contato com a inteligência humana, renovando-se e trazendo novas soluções para problemas. Assim, quando surgem os aparelhos na economia capitalista, surge um novo tipo de trabalhador: o funcionário. O funcionário não está interessado mais em resolver problemas e utilizar máquinas para ajudar na resolução, como antigamente faziam os operários. Funcionários possuem aparelhos que já tem a solução para uma infinidade de problemas. Então, este homem não trabalha mais, mas brinca com os aparelhos. Ela não se encontra cercado de coisas, instrumentos, máquinas, mas encontra-se no interior dos aparelhos. Assim, funcionário e aparelho se confundem, suas inteligências se mesclam, uma desenvolvendo a outra.

As possibilidades do programa são quase inesgotáveis e o jogo consiste no funcionário tentar esgotar ao máximo esse jogo, que o impele sempre para novos desafios. Como as câmeras fotográficas são aparelhos, fotógrafos são funcionários. As imagens técnicas produzidas no interior de sua câmara obscura são produtos desse jogo e promovem o jogo fora da câmara: "a nova magia é a ritualização de programas, visando programar seus receptores para um comportamento mágico programado". (FLUSSER, 2011, 27). A magia das imagens técnicas vem de um modelo científico que pré-programa 0 encantamento e programa os comportamentos - tanto de quem as produz como de quem entra em contato com elas - reproduzindo em uma rede infinita esta magia. Portanto, a fotografia veio tornar o mundo mais imaginativo e revolucionou as relações culturais:

O propósito das imagens técnicas era reintroduzir as imagens na vida cotidiana, tornar imagináveis os textos herméticos e tornar visível a magia subliminar que se escondia nos textos baratos. Ou seja, as imagens técnicas (e, em primeiro lugar, a fotografia) deviam construir um denominador comum entre conhecimento científico, experiência artística e vivência política. (FLUSSER, 2011, 29)

A fotografia, então, reunificou a cultura. O processo de tornar os textos científicos mais acessíveis - as revistas sobre os assuntos mais diversos e complexos, utilizam-se do recurso da imagem para facilitar a compreensão do consumidor - ou de tornar os textos literários ainda mais mágicos - através do cinema, por exemplo - acabou fazendo os textos "descerem à Terra". 
Proporcionou um maior acesso, democratizou a cultura e por isso contribuiu também politicamente. Ela conseguiu unificar esses setores através da sua capacidade informadora. Informar no sentido literal de dar forma, ou seja, reconfigurar a realidade segundo um modelo e este, como já falamos anteriormente, é o programa.

A linguagem simbólica programada é um jogo relativamente fácil de jogar, pois o aparelho dispõe sempre de inúmeras possibilidades - por isso a democratização. É fácil para qualquer um entrar na brincadeira. Brincando com o jogo, os homens aprendem a jogar, ensinam ao programa novas saídas e as inteligências vão mutuamente trocando informações e se desenvolvendo. No aparelho fotográfico quem, em primeiro plano brinca, é o fotógrafo. Este manipula símbolos, cria novos, armazena e os reproduz. Esses símbolos - as imagens - informam, ou seja, dão a forma do programa para quem as vê. E esses que as veem passam a aprender a jogar e reproduzem o modelo (ou a brincadeira).

O fotógrafo brinca para esgotar o programa do aparelho fotográfico que 0 desafia paulatinamente. Ele não quer mudar o mundo, mas esgotar as possibilidades do jogo, brincando com o aparelho de maneira mutuamente desafiadora: ele capta a realidade driblando não só as condições do programa, mas as condições culturais. Através de uma atitude de caçador, que contrai todo o seu corpo para capturar a presa, o fotógrafo vai buscando, através do programa, achar perspectivas diversas, tirando os objetos do uso comum - tanto o modelo comum do programa, como o modelo comum da cultura programada. Flusser salienta que "o fotógrafo se emancipa da condição cultural graças ao seu jogo com as categorias". (FLUSSER, 2011, 45)

O fotógrafo quer descobrir cenas, não a realidade objetiva. $O$ aparelho e o fotógrafo transcodificam a realidade processual em cenas fixas e, por isso, mágicas. Mas tais cenas não são simplesmente produtos da realidade, elas passaram pelo interior do aparelho. Tecnicizaram-se, ou seja, conceituaram-se. A magia agora é de outro tipo. Um tipo em que a simulação do real é mais poderosa e de um alcance nunca visto antes. $O$ fotógrafo não quer ver através do olho nu, mas quer ver através da câmera, isto é, ver e produzir cenas jamais vistas com as inúmeras possibilidades que tem em suas mãos. Quando as 
fotografias são produzidas, elas vêm carregadas dessas informações: conceitos resultantes de dribles do programa e da cultura. No entanto, elas acabam informando a cultura, criando uma malha infinita de símbolos. O fotógrafo vê a malha, onde a condição cultural se esconde entre suas tramas: "O gesto fotográfico desmente todo realismo e idealismo. As novas situações se tornarão reais quando aparecerem na fotografia". (FLUSSER, 2011, 47)

O mundo, portanto, torna-se uma espécie de colcha de retalhos de imagens. $O$ jogo se naturalizou de tal maneira, que nem nos damos conta do quanto somos cercados por imagens. Cada objeto que nos circunda vem repleto de símbolos. Os próprios objetos tornam-se símbolos dotados de significados mágicos. Um sapato diz mais sobre a identidade de uma pessoa, que sua própria família. A imagem é onipresente e nossas próprias vidas tornaram-se imagem: as redes sociais e o YouTube são provas cabais que hoje ultrapassamos o sonho dos quinze minutos de fama. Encenamos vinte quatro horas nossas próprias vidas: "o novo homem não é mais uma pessoa de ações concretas, mas sim um performer (Spieler): Homo ludens e não Homo faber" (FLUSSER, 2017, 54).

Esse homem que cria a si mesmo a partir das imagens, esse mundo flutuante, fragmentado, não surgiu da noite para o dia. Flusser afirmou que 0 tempo das imagens técnicas é a pós-história, o momento em que nossa compreensão de tempo não segue mais a linearidade histórica, o que permite nos conectarmos com qualquer momento, compreendendo as relações íntimas e significativas que ultrapassam a cronologia. Seguindo a não linearidade da atualidade, retornemos ao pensamento de Walter Benjamin, que anteviu e compreendeu profundamente, há mais de oitenta anos, o que estamos vivendo tão intensamente nos dias de hoje.

\section{0 espaço de imagens}

No ensaio O Surrealismo: o último instantâneo da inteligência europeia, de 1929, Benjamin busca entender como o movimento surrealista captou, de maneira revolucionária, a nova vida que se instaurava a partir das imagens, traduzindo isso através da literatura, das artes plásticas e da fotografia. $O$ surrealismo absorveu a nova estrutura social que estava começando a se formar 
e expressou seu fundamento compreendendo o cerne revolucionário que a constituía. Essa expressão se desenvolveu pela manifestação do inconsciente. Tal instância é uma condição de encobrimento, ocultamento, na qual a mente opera. Todas as situações cotidianas ocultadas estão armazenadas no âmbito do inconsciente, mas apesar de não percebidas, manifesta-se constantemente em todos os atos do dia-a-dia. O surrealismo quis expressar esse universo de coisas encobertas e, principalmente, captar o que estava encoberto na rotina. A linguagem dos sonhos e o que há de onírico no sempre mesmo que nos cerca foi a tônica surrealista.

O surrealismo brotou em meio a todas as transformações causadas pelo surgimento da fotografia. Benjamin compreendeu o valor mágico que a técnica deu às imagens e chamou o espaço onírico das imagens de inconsciente ótico. O valor mágico das imagens está, segundo Benjamin, no seu caráter de eterno retorno, pois mesmo que o fotógrafo tente a todo custo planejar suas imagens a partir de um comportamento, quem as vê sempre busca:

(...) a pequena centelha do acaso, do aqui e agora, com a qual a realidade chamuscou a imagem, de procurar o lugar imperceptível em que o futuro se aninha ainda hoje em minutos únicos, há muito extintos, e com tanta eloquência que podemos descobri-lo olhando para trás. (BENJAMIN, 1994, 95).

A visão da câmera fotográfica é a visão do minuto único que fragmenta a relação entre o espaço e o tempo. Olhar para uma imagem é buscar no sempre mesmo o futuro e poder, através do novo, entender o passado. O olhar que circula o espaço da imagem, sempre retorna e sempre produz novos significados, nos conectando com o mesmo espaço do sonho, onde a linearidade entre passado, presente e futuro não existe. Por isso, Benjamin e Flusser compartilham da mesma concepção, dado que é através da capacidade técnica da câmera fotográfica que se produz a magia das imagens. Essa capacidade técnica traz à tona o que estava encoberto, o que o olho nu não tem condição de ver e a consciência condição de fixar. A ampliação ou a câmera lenta abrem espaço para as coisas ocultas e significativas, ou seja, o inconsciente ótico: o espaço do encoberto, espaço dos sonhos produzido pelas imagens.

A fotografia surrealista abriu espaço para as primeiras técnicas de fotomontagem e através de uma brincadeira de ângulos e objetos deslocados do 
uso comum, o surrealismo deu condições de alcançarmos o absurdo cotidiano. ${ }^{4}$ Benjamin chamou atenção para o caráter de construção trazido pelo surrealismo à técnica fotográfica, que desde então, já estava submersa em relações fetichizadas do capitalismo. Essas fotografias a serviço da moda, segundo Benjamin, apesar do seu lado também onírico, estão em busca de uma falsa reprodução da realidade - ou, como Flusser apontou, estão buscando ser "janelas". Uma tentativa pobre de criar um mundo preparado. A construção surrealista da imagem fotográfica quebra com a lógica e insere o ilógico afim de criar uma realidade notoriamente artificial. Essa experimentação provoca aprendizado e conhecimento, tira o homem de um estágio de torpor, ou alucinação. Benjamin critica:

A verdadeira realidade transformou-se na realidade funcional. As relações humanas, reificadas - numa fábrica, por exemplo - não mais se manifestam. É preciso, pois, construir alguma coisa, algo de artificial, de fabricado. O mérito dos surrealistas é o de ter preparado 0 caminho para essa construção fotográfica. (BENJAMIN, 1994, 106)

O filósofo chama atenção sobre como o movimento surrealista quebra com o caráter funcional do mundo através da embriaguez do inconsciente. Ele alerta que a embriaguez pode se instaurar na mente em seu estado mais pleno de consciência, alertando inclusive sobre como a embriaguez da mente pode ser mais perigosa que qualquer outro narcótico. ${ }^{5} \mathrm{~A}$ mente é algo em que estamos encarcerados. Escolher se entorpecer através de meios externos é menos perigoso, pois seu efeito não é contínuo. O efeito do torpor da consciência é contínuo e só há uma forma de rompermos com esse transe: nos permitindo retomarmos às nossas próprias instâncias ocultas. Por isso, Benjamin fala sobre o caráter revolucionário da linguagem do inconsciente motivada pelo surrealismo.

\footnotetext{
${ }^{4}$ Alguns dos grandes nomes da fotografia surrealista são: Dora Maar, Man Ray, Manuel Álvarez Bravo, Maurice Tabard, Lee Miller, Raoul Ubac, dentre outros artistas fantásticos que captaram com tanta sensibilidade o absurdo do prosaico.

5 "O home que lê, que pensa, que espera, que se dedica à flânerie, pertence, do mesmo modo que o fumador de ópio, o sonhador e o ébrio, à galeria dos iluminados. E são os iluminados mais profanos. Para não falar da mais terrível de todas as drogas - nós mesmos - que tomamos quando estamos sós". (BENJAMIN, 1994, 33)
}

Mestre em Filosofia pela Universidade Estadual do Ceará. Pesquisadora do Grupo "Walter Benjamin e a Filosofia Contemporânea" (Cnpq). Brasileira, residente em Fortaleza-CE. Email: 
A iluminação profana é uma ótica dialética que compreende o que há de onírico na realidade mais prosaica. A capacidade de enxergar o transe existente no estado de coisa aparentemente normal. Os mantras entoados por algumas religiões nada mais são que a repetição de frases de maneira ininterrupta, que leva a mente e o corpo a um estado de completo torpor. O cotidiano nos leva ao transe, quando continuamente repetimos a mesma ordem de coisas que nos posiciona no estado de normalidade. Trazer à tona o inconsciente é abalar esse estado de normalidade que constitui a identidade: "Na estrutura do mundo, o sonho mina a individualidade, como um dente oco. Mas o processo pelo qual a embriaguez abala o Eu é ao mesmo tempo a experiência viva e fecunda que permitiu a esses homens fugir ao fascínio da embriaguez" (BENJAMIN, 1994, 23).

Os homens que permitem a si mesmo se embriagar pelas instâncias do inconsciente, seja através da arte, ou através dos narcóticos, estes homens estão preparados para lidar melhor com o encantamento e torpor do estado de normalidade. No entanto, a iluminação profana é o estágio em que a inteligência humana alcança uma criatividade de inspiração "materialista e antropológica" (BENJAMIN, 1994, 23), ou seja, o narcótico não é uma etapa essencial para esse estágio de compreensão da tessitura que compõe a mente e a realidade. É uma iluminação que nos abre a compreensão sobre a dialética entre oculto e visível, real e irreal.

Existe uma magia nas "coisas escravizadas e escravizantes" (BENJAMIN, 1994, 25). Essa magia está para além do fetiche, atrás dele não se esconde 0 real, mas outros mundos, plurais e numerosos que nos salvam da miséria das coisas mesmas: "só devassamos o mistério na medida em que o encontramos no cotidiano, graças a uma ótica dialética que vê o cotidiano como impenetrável e o impenetrável como cotidiano" (BENJAMIN, 1994, 33). Assim, viver nesse espaço do onírico é diretamente viver no espaço de imagens. Driblar a condição cultural do torpor, da reificação, é entender a magia que há por trás de todas as coisas ao redor. Viver nesse espaço de imagens é entender que nada mais pode ser mensurado segundo o parâmetro da Realidade. Esse pressuposto morreu, uma vez que nosso mundo se tornou excessivamente construído e artificial e já não sabemos mais os limites definidores entre cultura e natureza. Dessa 
maneira, a fotografia criou uma nova trama por onde caminhamos, de maneira muito insegura e desajeitada.

Sobre a teia de imagens e o novo espaço produzido por ela, Benjamin afirmou:

(...) em toda parte em que uma ação produz a imagem a partir de si mesma e é essa imagem, extrai para si essa imagem e a devora, em que a própria proximidade deixa de ser vista, aí se abre esse espaço de imagens que procuramos, o mundo em sua atualidade completa e multidimensional, no qual não há lugar para qualquer 'sala confortável', o espaço, em uma palavra, no qual o materialismo político e a criatura física partilham entre si o homem interior, a psique, o indivíduo, ou o que quer que seja que desejemos entregar-lhes, segundo uma justiça dialética, de modo que nenhum de seus membros deixe de ser despedaçado. (BENJAMIN, 1994, 35)

Tal lugar que se configura como uma realidade criadora de imagens, que cria a si mesma através das imagens e também destrói a si mesma na destruição inevitável das imagens. Tal justiça dialética, que não deixa nenhuma imagem inteira, é o que produz o desconforto de um mundo que produz ícones para imediatamente rasga-los, destruí-los. Esse homem do interior, do materialismo político, diante do mundo de imagens, tem se diluído. O corpo não é mais um produto do interior, da identidade, mas um produto externo do espaço de imagens e continuamente o corpo deseja ampliar-se nesse espaço.

O que a fotografia surrealista iniciou, a brincadeira com imagens, o jogo com a realidade, é algo que não é mais privilégio de um grupo seleto de artistas e intelectuais. A massa hoje brinca com a própria imagem nos inúmeros aplicativos de smartphones. Todos hoje em dia tornaram-se ícones participantes de um domínio público. ${ }^{6}$ Por conseguinte, progressivamente não entendemos

\footnotetext{
${ }^{6}$ Quando Benjamin fala sobre o ator cinematográfico, nota uma diferença entre o ator de teatro e o que interpreta no cinema, pois este representa a si mesmo. Como a câmera tem esse potencial técnico de captar as imagens de muitos ângulos e enquadramentos, trazendo todos os detalhes do macro ou do micro, o ator deixou de encarnar na sua expressividade corporal todas as nuances interpretativas, pois agora cabe ao jogo de imagens trazer ao público as sensações: "é menos importante que o interprete represente um personagem diante do público que ele represente a si mesmo diante da câmara. $O$ ator cinematográfico típico só representa a si mesmo" (BENJAMIN, 1994, 182). Essa autorepresentatividade abriu espaço para que houvesse maior identificação entre público e artistas, trazendo para as massas o impulso de realizar o desejo de exposição. Por isso Benjamin completa dizendo: "Cada pessoa, hoje em dia, pode reivindicar o direito de ser filmado" (BENJAMIN, 1994, 183). A técnica rompeu o distanciamento e tornou-se plataforma para todas as vozes.

Mestre em Filosofia pela Universidade Estadual do Ceará. Pesquisadora do Grupo "Walter Benjamin e a Filosofia Contemporânea" (Cnpq). Brasileira, residente em Fortaleza-CE. Email: liafreitasoliveira@gmail.com
} 
mais a relação entre interior e exterior, natural e artificial, verdade ou mentira. Tudo entrou na fluidez da trama escorregadia desse espaço.

Benjamin chama atenção sobre este fenômeno desde os primórdios da fotografia, quando Eugène Atget ${ }^{7}$ fotografava as ruas vazias de Paris. Atget enveredou por uma trajetória completamente diferente dos fotógrafos da época, ainda especializados em retratos. Benjamin fala sobre esse tema no ensaio $A$ pequena história da fotografia, de 1931, e comenta que a atitude de Atget serviu para "libertar o objeto da sua aura" (BENJAMIN, 1994, 101). No mesmo ensaio, o filósofo fala que o retrato é o último reduto da aura, por ainda conter a figura do rosto humano como refúgio de uma aparição única, ou o refúgio da identidade. Mas o processo de declínio da aura foi gradativo, e Atget fez parte da moderna escola de fotografia que se desvencilhou de tais parâmetros, conseguindo captar o novo clima cultural que começava a se estabelecer. Assim, ao fixar as cenas das ruas vazias de Paris, o fotógrafo devassou uma realidade ainda presa na singularidade, enxergando um espaço vazio de sujeitos $^{8}$. Nossa cultura encontra-se hoje como as ruas de Paris capturadas por Atget no início do século XX: um ambiente vazio de sujeitos.

Hoje cada um é uma imagem de si, essa imagem não mais tem a ver com uma identidade pautada no Eu, mas em uma construção muito fluida, onde o importante não está no "ser", nem mesmo no experimentar, mas só no vivenciar. Somos recortes de cada uma dessas vivências e somos ícones dessas vivências para os outros. Nossos pensamentos estão todos instantaneamente registrados nas redes sociais. Todos os momentos informamos os outros sobre nós mesmos e proporcionamos um espetáculo para quem nos assiste.

Quando Benjamin fala sobre o Camundongo Mickey no famoso ensaio $A$ obra de arte na era de sua reprodutibilidade técnica, de 1936, começa na primeira parte do trecho falando a seguinte frase:

Uma das funções sociais mais importantes do cinema é criar um equilíbrio entre o homem e o aparelho. O cinema não realiza essa tarefa apenas pelo modo com que o homem se representa diante do

\footnotetext{
$71857-1927$

8 Benjamin também chama atenção para o fato de que "as fotos parisienses de Atget são as precursoras da fotografia surrealista, a vanguarda do único destacamento verdadeiramente expressivo que o surrealismo conseguiu pôr em marcha". (BENJAMIN, 1994, 100)

Mestre em Filosofia pela Universidade Estadual do Ceará. Pesquisadora do Grupo "Walter Benjamin e a Filosofia Contemporânea" (Cnpq). Brasileira, residente em Fortaleza-CE. Email: 
aparelho, mas pelo modo com que ele representa o mundo, graças ao aparelho. (BENJAMIN, 1994, 189)

Isso significa que o aparelho se tornou, graças ao desenvolvimento da reprodutibilidade técnica, uma espécie de mediador entre homem e mundo. Olhamos o mundo através dos aparelhos e entendemos o mundo conforme os aparelhos. O mundo fantástico, antes privilégio do personagem Mickey como representante de toda a magia daquele universo fictício, tornou-se o nosso mundo. Assim, não existe mais "olho nu", pois nosso olho vê conforme o aparelho. Desconfiamos dos nossos olhos, sabemos que precisamos do aparelho para enxergar as coisas ocultas. Nos tornamos, portanto, o "personagem do sonho coletivo" (BENJAMIN, 1994, 190) graças aos aparelhos e suas infinitas possibilidades de resolução de problemas.

\section{Flusser e Benjamin: diálogos sobre a imagem}

Um elemento importantíssimo que liga o pensamento de Walter Benjamin e Vilém Flusser acerca da compreensão sobre as imagens, é a visão do fragmento. As imagens, como superfícies que fixam cenas, são sempre fragmentos, recortes. O próprio cinema nasce da justaposição de recortes de imagens, que criam o movimento. Benjamin, inclusive, observa que através dos golpes causados pelos cortes constantes de imagens, ou seja, o salto de uma cena para outra, provoca no espectador uma espécie de liberação catártica e educa o espectador a conviver com os choques rotineiros da vida moderna. ${ }^{9} \mathrm{Ou}$ seja, a vivência da imagem está longe de ser somente ótica, mas é corpórea. A imagem informa o corpo segundo suas características, dessa maneira, o corpo do homem contemporâneo se constrói dentro do parâmetro fragmentário das imagens. E sobre essa característica, Flusser também afirma:

(...) o caráter de camaleão no universo fotográfico, sua coloração cambiante, não passa de fenômeno de 'pele'. Quanto a estrutura

\footnotetext{
${ }^{9}$ Ainda sobre o caráter terapêutico que o cinema pode trazer, Benjamin ressalta: "A hilaridade coletiva representa a eclosão precoce e saldável dessa psicose de massa. As enormes quantidades de episódios grotescos atualmente consumidos no cinema constituem um índice impressionante dos perigos que ameaçam a humanidade, resultantes das repressões que a civilização traz consigo. Os filmes grotescos, dos Estados Unidos, e os filmes da Disney, produzem uma explosão terapêutica do inconsciente". (BENJAMIN, 1994, 190)

Mestre em Filosofia pela Universidade Estadual do Ceará. Pesquisadora do Grupo "Walter

Benjamin e a Filosofia Contemporânea" (Cnpq). Brasileira, residente em Fortaleza-CE. Email: liafreitasoliveira@gmail.com
} 
profunda o universo fotográfico é um mosaico. Muda constantemente de aspecto e cor, como mudaria um mosaico onde as pedrinhas seriam constantemente substituídas por outras. (...) Trata-se pois de universo quântico, calculável (cálculo = pedrinha), atomizado, democritiano, composto de grãos, não de ondas, funcionando como quebra cabeças, como jogo de permutação de elementos claros e distintos. (FLUSSER, 2011, 83)

Quem estuda a filosofia benjaminiana percebe prontamente que os termos usados por Flusser no trecho acima, são os mesmos usados por Benjamin em sua teoria. A questão do mosaico e a concepção atomizada, remetem bastante à questão monadológica que fundamenta a perspectiva benjaminiana sobre a modernidade. ${ }^{10} \mathrm{O}$ diálogo é claramente direto entre ambos. Esse universo quântico observado por Flusser também remete ao salto. O autor analisa que o caráter quântico da cultura das imagens elimina a noção processual. É uma cultura que vive de saltos, assim como os elementos quânticos. Ou seja, vive do corte, do súbito produzido por tudo que é instantâneo. Por isso não somos mais seres históricos, mas seres pós-históricos: o salto nunca é linear, nem tem um telos, pois subitamente acontece e desloca o elemento para qualquer parte.

O universo fragmentário das imagens por sua fluidez constituinte, também dissolve as coisas ao redor. Flusser destaca o fato de estarmos vivendo a era das não-coisas e essas nada mais são que as informações. Estas são impalpáveis, são apenas decodificáveis. A informação é produto da linguagem de programas. Vivemos uma nova fase do sistema capitalista, a qual não existe mais as antigas relações de trabalho focadas para a produção de objetos,

\footnotetext{
10 Em sua teoria do conhecimento, desenvolvida da obra Origem do drama barroco alemão, escrita em 1925, Benjamin faz uma crítica ao pensamento de algumas doutrinas filosóficas de caráter sistemático, como o idealismo alemão, por exemplo. Essa crítica preza por uma visão filosófica que tenha como método não mais a teleologia da síntese dialética, mas o desvio como caminho para a compreensão da verdade. Então, através da diferenciação entre doutrina e tratado, Benjamin expõe qual perspectiva teórica deseja desenvolver: "A representação como desvio é, portanto, a característica metódica do tratado. Sua renuncia à intenção, em seu movimento contínuo: nisso consiste a natureza básica do tratado. Incansável, o pensamento começa sempre novo, e volta sempre, minunciosamente às próprias coisas" (BENJAMIN, 1984, 50). Dessa maneira, o filósofo faz um paralelo entre o tratado e o mosaico, pois enquanto no mosaico há as intermitências entre os fragmentos de imagens, há no tratado as intermitências entre os fragmentos de pensamento que proporcionam seu ritmo próprio: retorno minucioso às coisas mesmas, e a produção criativa do pensamento. É olhando o fragmento que podemos compreender verdadeiramente o todo. Partir do todo, é matar os fragmentos e aniquilar a capacidade criativa da inteligência. Por isso Benjamin se utiliza da concepção monadológica de Leibniz para ilustrar sua visão perspectivista sobre o fragmento.
}

Mestre em Filosofia pela Universidade Estadual do Ceará. Pesquisadora do Grupo "Walter Benjamin e a Filosofia Contemporânea" (Cnpq). Brasileira, residente em Fortaleza-CE. Email: 
nascidas na Revolução Industrial. Vivenciamos hoje um capitalismo com foco nos serviços e estes são prestados por funcionários que operam aparelhos. Aparelhos são resultado de não-coisas, ou seja, de informação, de programas.

A geração pós Revolução Industrial foi uma geração que produziu objetos e passou a vida preocupada em adquirir objetos para resolver problemas da vida até a chegada da morte. Hoje em dia a concepção mudou, pois como vimos anteriormente, programas são soluções automáticas de problemas. Assim Flusser alerta: "Estamos cada vez menos interessados em possuir coisas e cada vez mais querendo consumir informações" (FLUSSER, 2017, 51). Consequentemente, transferimos o valor das coisas para as informações, para não-coisas. A moral burguesa tem definhado gradativamente e abrindo espaço para uma nova moral. Transvaloramos esse mundo e o pouco das coisas que ainda nos restam são cada dia mais descartáveis e sem importância. A nova moral não vem mais pautada na concretude do mundo, mas na perspectiva volátil das informações.

Sobre a transvaloração que a técnica proporcionou à cultura, Benjamin se dá conta desse fenômeno a partir do processo de esmaecimento da concepção burguesa de interioridade, que está ligada diretamente à noção de identidade. $O$ homem burguês, pós Revolução Industrial, é esse ser rodeado de coisas. Cada objeto que o cerca é estofo de seu próprio ser. O espaço onde o burguês está é sempre manifestação de sua interioridade e cada objeto o ancora em si mesmo. Quando a técnica avança o desenvolvimento da massificação aos poucos vai minando essa relação e os limites entre interior e exterior passam a ficar gradualmente mais imprecisos.

Benjamin alerta para o surgimento de uma cultura onde a tendência é a total diluição desses limites e vê essa possibilidade como algo revolucionário: "Viver numa casa de vidro é uma virtude revolucionária por excelência. Também isso é embriaguez, um exibicionismo moral, que nos é extremamente necessário" (BENJAMIN, 1994, 24). Necessário porque é um rompimento de velhos valores e a inauguração de novos que proporcionam ao homem uma vivência de maior integridade consigo mesmo e com o exterior. Romper com essas barreiras é não ter medo de si, não precisar de coisas para se delimitar, é 
viver a expansão de sua própria imagem e se permitir ser atravessado pelas novas perspectivas.

Logo, no novo homem são muitas as perspectivas que se sincronizam, mesmo que opostas, assim como uma imagem. O espaço de liberdade para nos conectarmos com a multiplicidade do mundo é o que define - se ainda for possível falar de alguma definição para o homem contemporâneo. Benjamin, em sua pesquisa sobre o cinema, afirma:

\begin{abstract}
Veio então o cinema, que fez explodir esse universo carcerário com a dinamite dos seus décimos de segundo, permitindo-nos empreender viagens aventurosas entre as ruínas arremessadas à distância. (...) É evidente, pois, que a natureza que se dirige à câmara não é a mesma que se dirige ao olhar. A diferença está principalmente no fato de que o espaço em que o homem age conscientemente é substituído por outro em que sua ação é inconsciente. (BENJAMIN, 1994, 189)
\end{abstract}

A natureza que se dirige à câmera não é a mesma que se dirige ao olho nu, porque passou pela transcodificação do aparelho cinematográfico. A câmera abriu os horizontes humanos de maneira fantástica, trouxe perspectivas nunca antes imaginadas. A ação inconsciente proporcionada pelo aparelho está justamente no fato de que não usamos mais nossa inteligência para resolvermos problemas, usamos nossa inteligência quase sem muito esforço, de maneira dispersa, em conjunção com os aparelhos. Assim, moldamos nossos atos, nosso corpo, conforme o programa, sem nos darmos conta. Por isso para Benjamin o cinema tem o caráter terapêutico, porque sem tomar consciência, sem refletir sobre seu ato, o homem absorve e deixa sair de si comportamentos que poderiam ser prejudiciais a nível concreto. As imagens, então, através da expansão inconsciente, virtualizam o mundo, fragmentam-se em partes tão minúsculas que mal podemos perceber e definirmos suas fronteiras. Assim, o mundo não é mais um ambiente de objetos manipuláveis, mas um espaço de troca (jogo) de informações.

O homem contemporâneo é, portanto, uma montagem, uma simulação, que ele mesmo constrói involuntariamente com a ajuda dos suportes tecnológicos. Somos travessia de não-coisas, nada gruda, tudo perpassa, forma e desinforma e cria esse ser escorregadio, bem expresso na "natureza" do vidro. Benjamin, ao falar sobre as mudanças arquitetônicas na passagem do século XIX ao século $X X$, falou sobre o vidro ser esse material tipicamente moderno: 
"Não é por acaso que o vidro é um material tão duro e tão liso, no qual nada se fixa. É também um material frio e sóbrio. As coisas de vidro não têm nenhuma aura. O vidro é em geral inimigo do mistério. É também o inimigo da propriedade". (BENJAMIN, 1994, 117)

Somos escorregadios como o vidro, nada se fixa, nosso interior foi devassado pela técnica. Caminhamos para a simbólica Paris de ruas vazias de Atget, onde não há mais rastros de identidade. Ser alguém hoje em dia significa aparecer como evento. As plataformas online nos conectam com inúmeros acontecimentos ao redor do mundo e tornam a vida um espetáculo tão comum que se torna instigante. A vida do outro é instigante porque a lente proporciona um aumento do evento "real". Ver a mesma cena a olho nu não é interessante.

Ver pela tela torna-se fantástico. A mágica se perpetua porque a cena que criamos do mundo é reproduzida infinitamente. A quantidade de vezes da reprodução aumenta a proporção do evento e o efeito mágico que ele proporciona. Assim, mitificamos nossas imagens pela distorção da lente, da tela que engrandece os fatos, transformando-os em eventos. As informações flutuam por um universo não palpável e ao mesmo tempo são fixadas em uma "linha do tempo" que funciona como a tão sonhada máquina do tempo: retornamos ao nosso passado em um piscar de olhos. O tempo se dissolveu em um só.

\section{CONSIDERAÇÕES FINAIS}

Isto posto, é notório que a transformação da cultura através do processo de progressiva virtualização do mundo, começado pela fotografia, significa também uma metamorfose na constituição, na estrutura fundamental do ser contemporâneo. O novo homem que surge, pressentido pelos primeiros fotógrafos, como Atget, ou pelos artistas surrealistas, nasce e leva consigo uma nova etapa no desenvolvimento da civilização humana. Benjamin entendeu a primeira etapa da revolução, quando captou o surgimento das imagens e Flusser destrinchou a segunda etapa, a era da informática, da internet, como resultado inevitável do caminho. 
Os dois autores vislumbram as maravilhosas possibilidades que toda essa transformação trouxe e ainda pode trazer à civilização. No entanto, pelo olhar dialético, compreendem o caráter ambivalente de toda a situação. A ambivalência está na difícil tarefa humana em interpretar em que momento a magia nos impulsiona para a renovação constante de nossas potências, ou quando a magia se torna um impedimento criativo. Os dois autores não se interessam por receitas que direcionem passo a passo o que devemos fazer. Mas apontam para algumas possibilidades que cabe à nossa geração experimentar e assimilar suas ressonâncias.

Vilém Flusser escreve uma Filosofia da caixa preta na tentativa expressa de produzir uma filosofia do futuro. Nosso progresso técnico ainda não possibilitou ao homem o controle total sobre o tempo, então se pretendemos uma filosofia do futuro, essa reflexão só pode ainda se resumir como apontamentos do que podemos fazer no presente para produzirmos algo interessante para as gerações que virão. Se não quisermos cair numa repetição e nos tornar reféns dos aparelhos (como os pré-históricos se tornaram da imagem e os modernos do texto), Flusser alerta para a necessidade de entendermos o que se passa na câmara escura do aparelho fotográfico. É preciso cada vez mais um engajamento para devassarmos o que está oculto nas coisas aparentemente não ocultas. Segundo o filósofo isso só vai ser feito quando encararmos o jogo entre nós e os programas e compreendermos que a cada interação com os aparelhos, devemos manter nosso espaço de liberdade jogando contra eles. Isto significa jogarmos contra os aparelhos, driblarmos suas soluções e criar novos problemas. Não aceitar as soluções propostas pelo aparelho é uma maneira de continuarmos com nossa inteligência vívida, engajada na produção de um mundo livre.

Benjamin aponta para a necessidade de canalizar as forças da embriaguez para a revolução. Essa canalização se faz a partir de um posicionamento de desconfiança total. A iluminação profana se encontra no olhar dialético que sempre desconfia de qualquer unilateralidade. Não existe nada por trás das coisas. Quando Benjamin fala sobre o oculto, não é porque existe uma realidade por trás. Nessa sociedade ainda regimentada pelos discursos ideológicos, as coisas são o que são, no entanto, apressam-se por se organizar 
de forma unívoca, camuflando suas múltiplas perspectivas. O olhar iluminado será aquele que não se deixar enganar pelo jogo, mas através da brincadeira do olhar, entrar nesse jogo com o comprometimento de um jogador. Esse comprometimento envolve a disciplina da atenção constante e, ao mesmo tempo, a leveza da dispersão (ou da embriaguez), para compreender a rítmica em que o jogo acontece. $\mathrm{O}$ homem-ator contemporâneo só pode garantir seu lugar de protagonismo, quando se interessar pelas engrenagens que fazem com que as cortinas se levantem.

As pessoas têm sentido o caos dessa situação. Parece que a crise se tornou a normalidade. A falência de todas as instituições é o sintoma. As concepções políticas, morais, estéticas, estão todas girando no olho de um furacão que não sabemos bem qual a grandeza. No entanto, mesmo vendo a falência de todas os referenciais, ainda buscamos respostas nos antigos paradigmas. A tomada de consciência é uma delas. Não há mais como tomarmos consciência, precisamos tomar inconsciência para de fato produzirmos algo interessante para o novo que se aproxima. Isso significa que devemos abraçar a indefinição. A liberdade, então, poderia significar não mais um produto da razão (ou da maioridade), mas um estado corpóreo em que o corpo do homem, ou o corpo coletivo, brinca com a realidade como a criança brinca de ser o que a imaginação quiser.

\section{REFERÊNCIAS}

BENJAMIN, Walter. Magia e técnica, arte e política: ensaios sobre literatura e história da cultura. Tradução: Paulo Sérgio Rouanet. São Paulo: Brasiliense, 1994.

Origem do drama barroco alemão. Tradução: Paulo Sérgio Rouanet. São Paulo: Brasiliense, 1984.

FLUSSER, Vilém. Filosofia da caixa preta: ensaios para uma futura filosofia da fotografia. São Paulo: Annablume, 2011.

O mundo codificado: por uma filosofia do design e da comunicação. Tradução: Raquel Abi-Sâmara. São Paulo: Ubu Editora, 2017. 